\title{
New cross section measurements for the production of the Auger electron emitters ${ }^{77} \mathrm{Br}$ and ${ }^{80 \mathrm{~m}} \mathrm{Br}$
}

\author{
By I. Spahn ${ }^{1, *}$, G. F. Steyn ${ }^{2}$, C. Vermeulen ${ }^{2}$, Z. Kovács ${ }^{3}$, F. Szelecsényi ${ }^{3}$, M. M. Shehata ${ }^{1, \#, ~ S . ~ S p e l l e r b e r g ~}{ }^{1}$, B. Scholten ${ }^{1}$, \\ H. H. Coenen ${ }^{1}$ and S. M. Qaim ${ }^{1}$ \\ 1 Institut für Neurowissenschaften und Medizin, INM-5: Nuklearchemie, Forschungszentrum Jülich GmbH, 52425 Jülich, Germany
2 iThemba LABS, P.O. Box 722, Somerset West 7129, South Africa
3 Cyclotron Department, Institute of Nuclear Research of the Hungarian Academy of Sciences (ATOMKI), Debrecen 4026, Hungary
}

(Received March 18, 2010; accepted in revised form June 15, 2010)

\author{
${ }^{77} \mathrm{Br} /{ }^{80 \mathrm{~m}} \mathrm{Br} /$ Intermediate energy / \\ Proton induced reaction / Excitation function / \\ Integral yield / Radionuclide production
}

\begin{abstract}
Summary. The two Auger electron emitting radionuclides of bromine, namely ${ }^{77} \mathrm{Br}\left(T_{1 / 2}=57.04 \mathrm{~h}\right)$ and ${ }^{80 \mathrm{~m}} \mathrm{Br}\left(T_{1 / 2}=4.4 \mathrm{~h}\right)$, are promising candidates for internal radiotherapy. In this work, nuclear reaction cross sections were determined for their production using enriched Se targets. Thin Se samples were irradiated with incident protons of energies up to $85 \mathrm{MeV}$ and the induced radioactivity was measured via nondestructive $\gamma$-ray spectroscopy, allowing the determination and extension of the excitation functions of the four reactions ${ }^{77,78,80} \mathrm{Se}(p, x n)^{77} \mathrm{Br}$ and ${ }^{80} \mathrm{Se}(p, n)^{80 \mathrm{~m}} \mathrm{Br}$. The possible thick target yields were calculated and the different production routes discussed, especially with regard to the yield and the radionuclidic purity of the produced radionuclides.
\end{abstract}

\section{Introduction}

Today, the use of radioactive isotopes is well established in many fields of the life sciences. In particular, the application of radionuclides in diagnostic medical procedures such as positron emission tomography (PET) and single photon emission computed tomography (SPECT), as well as in internal radiotherapy, is becoming increasingly important. Whereas nuclear reactors are still providing the bulk of the production, in recent years the utilisation of accelerators has grown significantly due to an increasing demand for neutron deficient radionuclides and the simpler and less expensive operation of typical medical cyclotron facilities. As a result of this growth in accelerator produced radionuclides in medical applications, the demand on production efficiency while maintaining radionuclidic purity is also increasing. Besides being of interest for the development of nuclear models, the measurement of nuclear reaction cross sections over a broad energy range is also a crucial step in the determination of optimum conditions for a production route.

\footnotetext{
*Author for correspondence (E-mail: i.spahn@fz-juelich.de).

" Research scholar from Nuclear Research Centre, Atomic Energy Authority, Cairo, Egypt.
}

The application of radioisotopes of bromine in nuclear medicine is of longstanding interest. The production of the lighter isotopes, ${ }^{75} \mathrm{Br}\left(T_{1 / 2}=1.6 \mathrm{~h}\right)$ and ${ }^{76} \mathrm{Br}\left(T_{1 / 2}=16.2 \mathrm{~h}\right)$, and their use in PET imaging has been pursued for quite some time [1-4], and in a recent work [5] we discussed their production possibilities via intermediate energy reactions. In contrast, the two Auger electron emitters ${ }^{77} \mathrm{Br}$ $\left(T_{1 / 2}=57.04 \mathrm{~h}\right)$ and ${ }^{80 \mathrm{~m}} \mathrm{Br}\left(T_{1 / 2}=4.4 \mathrm{~h}\right)$ investigated in this work are of interest in internal radiotherapy. The utilisation of bromine for radiopharmaceutical synthesis bears some advantages due to its high chemical versatility, including high nucleophilicity and the possibility of in situ oxidation, enabling also electrophilic substitution $[2,6,7]$. The relevant decay properties [Ref. 8] of these two radionuclides are given in Table 1.

The production of ${ }^{77} \mathrm{Br}$ and ${ }^{80 \mathrm{~m}} \mathrm{Br}$ has been investigated using different nuclear processes [9-15] ( $c f$. Table 1). Concerning the production of ${ }^{77} \mathrm{Br}$, several routes have been investigated $[9,10,14,15]$, including proton induced reactions on Se targets, $\alpha$-particle induced reactions on As ( $c f$. [10]) and indirect routes via the formation of the precursor ${ }^{77} \mathrm{Kr}$, utilising the nuclear processes ${ }^{79} \mathrm{Br}(p, 3 n){ }^{77} \mathrm{Kr} \rightarrow$ $\left.{ }^{77} \mathrm{Br},{ }^{79} \mathrm{Br}(d, 4 n)\right)^{77} \mathrm{Kr} \rightarrow{ }^{77} \mathrm{Br}$ and ${ }^{\text {nat }} \mathrm{Se}\left({ }^{3} \mathrm{He}, x n\right){ }^{77} \mathrm{Kr} \rightarrow$ ${ }^{77} \mathrm{Br}\left(c f\right.$. [14, 16-19]). Regarding the production of ${ }^{80 \mathrm{~m}} \mathrm{Br}$, deuteron induced reactions on $\mathrm{Kr}$ were investigated [11]. Although all those production routes lead to high-purity products, the resulting radionuclide yields are rather low. In the case of ${ }^{77} \mathrm{Br}$, the intermediate energy reaction appears to be promising but the data are scanty. For ${ }^{80 \mathrm{~m}} \mathrm{Br}$, the production database is rather weak.

The aim of this work was to determine nuclear reaction cross sections using enriched selenium isotopes as target material to be able to develop efficient routes for the production of radionuclidically pure ${ }^{77} \mathrm{Br}$ and ${ }^{80 \mathrm{~m}} \mathrm{Br}$. The short-lived isotope ${ }^{80 \mathrm{~g}} \mathrm{Br}\left(T_{1 / 2}=17.6 \mathrm{~min}\right)$ has no relevance for medical applications and was therefore not part of this study. The cross section data for the production of ${ }^{77} \mathrm{Br}$ via low energy $(p, n)$ and $(p, 2 n)$ reactions have already been well determined [20]. In this work those measurements were extended by studying the nuclear processes ${ }^{77,78,80} \mathrm{Se}(p, x n){ }^{77} \mathrm{Br}$, using enriched target materials. The excitation function of the ${ }^{80} \mathrm{Se}(p, n){ }^{80 \mathrm{~m}} \mathrm{Br}$ reaction was determined systematically up 
Table 1. Decay properties of the radionuclides ${ }^{77} \mathrm{Br}$ and ${ }^{80 \mathrm{~m}} \mathrm{Br}$ and some of their investigated production routes. ${ }^{a}$

\begin{tabular}{|c|c|c|c|c|c|}
\hline & $\begin{array}{l}\text { Half- } \\
\text { life (h) }\end{array}$ & $\begin{array}{l}\text { Decay } \\
\text { mode }\end{array}$ & $\begin{array}{l}\text { Main } \gamma \text {-rays } \\
\text { in } \mathrm{keV}(\%)\end{array}$ & $\begin{array}{l}\text { Previously investigated } \\
\text { production routes }\end{array}$ & $\begin{array}{l}Q \text {-value } \\
(\mathrm{MeV})\end{array}$ \\
\hline${ }^{77} \mathrm{Br}$ & 57.04 & $\begin{array}{c}\beta^{+} \\
(0.74 \%) \\
\text { EC } \\
(99.26 \%) \\
\text { Auger } \\
\text { electrons }\end{array}$ & $\begin{array}{r}239.0 \\
(23.1) \\
520.6 \\
(22.4) \\
297.2 \\
(4.2)\end{array}$ & $\begin{array}{c}{ }^{75} \mathrm{As}(\alpha, 2 n)(c f .[10]) \\
\left.{ }^{79} \mathrm{Br}(d, 4 n)\right)^{77} \mathrm{Kr} \rightarrow{ }^{77} \mathrm{Br}[15] \\
{ }^{79} \mathrm{Br}(p, 3 n){ }^{77} \mathrm{Kr} \rightarrow{ }^{77} \mathrm{Br}[16] \\
\quad{ }^{\text {nat }} \mathrm{Se}(p, x n)[25]\end{array}$ & $\begin{array}{c}-13.515 \\
-24.983 \\
-22.824 \\
-2.147 \text { to } \\
-29.521\end{array}$ \\
\hline${ }^{80 \mathrm{~m}} \mathrm{Br}$ & 4.4 & $\begin{array}{c}\text { IT } \\
(100 \%) \\
\text { Auger } \\
\text { electrons }\end{array}$ & $\begin{array}{l}37.05 \\
(39.1)\end{array}$ & $\begin{array}{l}{ }^{80} \mathrm{Se}(p, n)[28] \\
{ }^{83} \mathrm{Kr}(d, \alpha n)[11] \\
{ }^{\mathrm{nat}} \mathrm{Se}(p, x n)[25]\end{array}$ & $\begin{array}{l}-2.652 \\
-1.453 \\
-2.652 \text { to } \\
-18.629\end{array}$ \\
\hline
\end{tabular}

a: Data taken from $[8,34]$.

to $20 \mathrm{MeV}$ for the first time. Based on the experimental cross section data, possible production yields of the investigated radionuclides were deduced. Furthermore, the important issues of radionuclidic purity and optimum production conditions are discussed on the basis of those yield data.

\section{Experimental}

Cross sections were determined via activation and identification of the radioactive products using non-destructive $\gamma$-ray spectroscopy. The relevant techniques are given below.

\subsection{Sample preparation}

For investigation of different nuclear processes, targets of enriched elemental ${ }^{77} \mathrm{Se}(91.77 \%),{ }^{78} \mathrm{Se}(98.58 \%)$ and ${ }^{80} \mathrm{Se}$ $(99.90 \%)$ powder were used, which were obtained from Oak Ridge National Laboratory and Chemotrade GmbH. The preparation of thin samples for irradiations using the sedimentation technique was described in detail in our recent publication [5]. Al foils of $100 \mu \mathrm{m}$ thickness were used as backings. Sediment layers were obtained, each having an enriched Se isotope content of $2.9-28.9 \mathrm{mg} / \mathrm{cm}^{2}$. The deposited layer had a diameter of either 7 or $10 \mathrm{~mm}$ and was covered by a thin $\mathrm{Al}$ foil for protection. This technique enables the preparation of thin Se layers with no or minimal loss of enriched material. However, the obtained samples are sensitive to pressure and interfacial tension. Both effects can potentially lead to the formation of small cracks and inhomogeneity of the target material. Thus handling of the samples had to be done avoiding bending and local pressure.

\subsection{Irradiations and beam current measurement}

The samples were irradiated in a stacked-foil arrangement together with different monitor foils, namely $\mathrm{Al}, \mathrm{Cu}$ and $\mathrm{Ni}$ (Goodfellow). The proton energy degradation within the stack was calculated at Jülich with the computer code STACK, which is based on the Bethe formalism and the tables of Williamson et al. [21] and with a similar code at iThemba LABS in Somerset West, based on the stopping power expressions of Anderson and Ziegler [22]. The two sets of calculations were in excellent agreement.
In investigations on the formation of ${ }^{77} \mathrm{Br}$, irradiations with protons up to an energy of $45 \mathrm{MeV}$ were done at the injector cyclotron of COSY of the Forschungszentrum Jülich, Germany. Irradiations in the higher energy region were carried out at the Separated Sector Cyclotron (SSC) of iThemba LABS in Somerset West, South Africa. The proton energy range covered by the irradiations was from 21 to $85 \mathrm{MeV}$. The thin ${ }^{77} \mathrm{Se}$ and ${ }^{78} \mathrm{Se}$ targets were irradiated at both cyclotrons with protons of energies up to $66 \mathrm{MeV}$. The ${ }^{80} \mathrm{Se}$ targets were irradiated with energies up to $85 \mathrm{MeV}$. The formation of ${ }^{80 \mathrm{~m}} \mathrm{Br}$ was studied only in the lower energy range up to $19 \mathrm{MeV}$, utilizing the Compact Cyclotron CV 28 of the Forschungszentrum Jülich. The energy ranges covered in the stacks were chosen such that they partly overlapped, thereby allowing a comparison of results in the overlapping regions, obtained in independent measurements.

The individual beam currents were measured in two different ways, involving current integration on the one hand, and the use of monitor reactions, on the other. The current integration was generally done using Faraday cups, whereas at iThemba LABS an activation chamber called RERAME was used, which is described in detail elsewhere [23]. As monitors, thin $\mathrm{Al}, \mathrm{Cu}$ and $\mathrm{Ni}$ foils were employed, utilizing the ${ }^{27} \mathrm{Al}(p, x)^{22} \mathrm{Na},{ }^{\text {nat }} \mathrm{Cu}(p, x n)^{62,63} \mathrm{Zn}$ and ${ }^{\text {nat }} \mathrm{Ni}(p, x)^{57} \mathrm{Ni}$ processes, respectively, the cross sections of which are well known [24]. The two methods of beam current determination generally showed an agreement within about $5 \%$.

\subsection{Measurement of radioactivity}

The induced radioactivity was measured non-destructively using HPGe detector $\gamma$-ray spectrometry, analysing all major $\gamma$-rays of the investigated radionuclides. The energy calibration and determination of counting efficiency were done using standard sources from PTB Braunschweig, Germany, and Amersham International, United Kingdom. All irradiated samples were analysed by registering several spectra at various times after the end of bombardment (EOB) and the results were averaged. The peak area analysis was done using either the software GammaVision 6.01 (EG\&G Ortec) or Emca 2000 version 2.03.0 (Silena International). In order to avoid losses of events from the relevant photopeaks due to 
coincidence summing, all measurements were done at a distance of $10-50 \mathrm{~cm}$ from the detector.

For measurements on ${ }^{80 \mathrm{~m}} \mathrm{Br}$, which emits only a lowenergy $\gamma$-ray of $37.1 \mathrm{keV}$, a well calibrated thin HPGe solid state detector (EG\&G Ortec) was used, which is equipped with an active diameter of $3.2 \mathrm{~cm}$, a depth of $1.3 \mathrm{~cm}$ and an $0.03 \mathrm{~mm}$ thick Be cover. Concerning the detection of ${ }^{77} \mathrm{Br}$, the possibility of interference caused by co-produced ${ }^{77} \mathrm{As}$ had to be considered. This was taken into account by analysing the rather weak $297.2 \mathrm{keV} \gamma$-ray of ${ }^{77} \mathrm{Br}$, which is not shared by its isobar, in addition to the two main $\gamma$-rays of energies 239.0 and $520.6 \mathrm{keV}$. Within the limits of uncertainty, no ${ }^{77}$ As activity was detected.

\subsection{Calculation of reaction cross sections and uncertainties}

The total uncertainties of the measurements were calculated according to Gaussian error propagation and are given together with the cross section data in Tables 2 and 3 . They are mainly based on the individual uncertainties of the incident proton energies, determination of particle flux and detector efficiency. Concerning the measurement of ${ }^{80 \mathrm{~m}} \mathrm{Br}$, the efficiency calibration is less precise than in general, leading to higher uncertainties in those cross section data. Largely, the total uncertainty in cross section amounted to between 9 and $20 \%$.

Cross sections were calculated using the well-known activation equation. As mentioned above, results obtained from the analysis of several clear $\gamma$-lines belonging to the same nuclide were averaged. The enriched isotopes had different abundances and all obtained cross section values were normalised to $100 \%$ enrichment of the respective target isotope.

\section{Results and discussion}

\subsection{Nuclear reaction cross sections}

The cross sections of the nuclear reactions ${ }^{77} \mathrm{Se}(p, n)^{77} \mathrm{Br}$, $\left.{ }^{78} \mathrm{Se}(p, 2 n){ }^{77} \mathrm{Br},{ }^{80} \mathrm{Se}(p, 4 n)\right)^{77} \mathrm{Br}$ and ${ }^{80} \mathrm{Se}(p, n){ }^{80 \mathrm{~m}} \mathrm{Br}$ were experimentally determined and the data relevant to the production of ${ }^{77} \mathrm{Br}$ and ${ }^{80 \mathrm{~m}} \mathrm{Br}$ are given in Tables 2 and 3, respectively, together with their corresponding uncertainties. The results for the ${ }^{77} \mathrm{Se}(p, n)^{77} \mathrm{Br}$ reaction between 21 and $35 \mathrm{MeV}$ were corrected for the contribution from the ${ }^{78} \mathrm{Se}(p, 2 n)^{77} \mathrm{Br}$ reaction, since the enriched material ${ }^{77} \mathrm{Se}$ contained $4.7 \%{ }^{78} \mathrm{Se}$. The cross section data for the latter reaction were measured independently in this work (see Sect. 3.1.2). This correction leads to the higher uncertainty given in Table 2 . In general, the results for ${ }^{77} \mathrm{Br}$ obtained from experiments done at the two different accelerators show good agreement. The ${ }^{80} \mathrm{Se}(p, 4 n)^{77} \mathrm{Br}$ reaction has been investigated for the first time in this work. Regarding the other reactions, the database was weak. Furthermore, those data were limited to the lower energy range and showed some deviations, which will be discussed in detail below. Most recently, El-Azony et al. [25] published their results on the formation of ${ }^{77} \mathrm{Br}$ and ${ }^{80 \mathrm{~m}} \mathrm{Br}$ via proton induced reactions on natural selenium up to $63 \mathrm{MeV}$.

The data measured in this work are shown as a function of proton energy, together with the corresponding literature
Table 2. Measured cross sections for the formation of ${ }^{77} \mathrm{Br}$, utilising the reactions as indicated.

\begin{tabular}{|c|c|c|c|}
\hline $\begin{array}{l}\text { Proton energy } \\
(\mathrm{MeV})\end{array}$ & \multicolumn{3}{|c|}{ Cross section (mb) } \\
\hline $21.3 \pm 0.9$ & $114 \pm 24$ & & \\
\hline $23.4 \pm 0.8$ & & $491 \pm 53$ & \\
\hline $24.3 \pm 0.8$ & $42 \pm 9$ & & \\
\hline $25.2 \pm 0.6$ & & $468 \pm 51$ & \\
\hline $26.6 \pm 0.8$ & $30 \pm 6$ & & \\
\hline $26.8 \pm 0.8$ & & $196 \pm 21$ & \\
\hline $27.0 \pm 0.5$ & & $167 \pm 18$ & \\
\hline $28.7 \pm 0.5$ & $15 \pm 3$ & & \\
\hline $29.5 \pm 0.5$ & & $110 \pm 12$ & \\
\hline $29.9 \pm 0.5$ & & $230 \pm 15$ & \\
\hline $30.9 \pm 0.7$ & & $253 \pm 27$ & \\
\hline $31.1 \pm 0.5$ & $16 \pm 3$ & & \\
\hline $31.5 \pm 0.5$ & $21 \pm 4$ & & \\
\hline $32.2 \pm 0.4$ & & $146 \pm 16$ & \\
\hline $32.5 \pm 0.4$ & & $117 \pm 13$ & \\
\hline $33.7 \pm 0.4$ & $16 \pm 3$ & & \\
\hline $34.1 \pm 0.4$ & $10 \pm 2$ & & \\
\hline $34.3 \pm 0.4$ & & $132 \pm 15$ & \\
\hline $34.5 \pm 0.4$ & & & $20 \pm 2$ \\
\hline $35.6 \pm 0.4$ & & $87 \pm 10$ & \\
\hline $35.7 \pm 0.4$ & $18 \pm 4$ & $100 \pm 11$ & \\
\hline $37.0 \pm 0.3$ & $12 \pm 3$ & & \\
\hline $37.2 \pm 0.3$ & & $126 \pm 14$ & \\
\hline $37.4 \pm 0.3$ & & & $98 \pm 11$ \\
\hline $38.4 \pm 0.6$ & & $60 \pm 7$ & \\
\hline $38.6 \pm 0.3$ & $23 \pm 5$ & & \\
\hline $39.9 \pm 0.2$ & $20 \pm 4$ & & \\
\hline $39.9 \pm 0.2$ & $12 \pm 2$ & $92 \pm 10$ & \\
\hline $40.6 \pm 0.5$ & & & $214 \pm 23$ \\
\hline $40.8 \pm 0.2$ & & $70 \pm 8$ & \\
\hline $41.4 \pm 0.2$ & $15 \pm 3$ & & \\
\hline $41.8 \pm 0.2$ & & $73 \pm 8$ & \\
\hline $42.4 \pm 0.2$ & & $67 \pm 7$ & \\
\hline $43.2 \pm 0.2$ & & $75 \pm 8$ & \\
\hline $43.2 \pm 0.5$ & & $65 \pm 7$ & \\
\hline $43.4 \pm 0.5$ & & & $231 \pm 25$ \\
\hline $43.7 \pm 0.2$ & $9 \pm 2$ & & \\
\hline $44.1 \pm 0.2$ & & $52 \pm 6$ & \\
\hline $44.5 \pm 0.2$ & $18 \pm 4$ & & \\
\hline $44.9 \pm 0.2$ & & $57 \pm 6$ & \\
\hline $44.9 \pm 0.5$ & & $77 \pm 8$ & \\
\hline $46.2 \pm 0.4$ & & & $189 \pm 21$ \\
\hline $48.4 \pm 0.3$ & $13 \pm 3$ & & \\
\hline $48.8 \pm 0.3$ & & & $216 \pm 24$ \\
\hline $51.3 \pm 0.3$ & & & $160 \pm 17$ \\
\hline $53.6 \pm 0.4$ & & $44 \pm 5$ & \\
\hline $53.9 \pm 0.3$ & & & $174 \pm 19$ \\
\hline $56.5 \pm 0.3$ & & & $122 \pm 13$ \\
\hline $56.6 \pm 0.2$ & $12 \pm 2$ & & \\
\hline $59.0 \pm 0.2$ & & & $73 \pm 8$ \\
\hline $59.3 \pm 0.3$ & & $45 \pm 5$ & \\
\hline $60.3 \pm 0.3$ & & & $31 \pm 3$ \\
\hline $61.4 \pm 0.2$ & & & $90 \pm 10$ \\
\hline $62.4 \pm 0.2$ & & & $81 \pm 9$ \\
\hline $63.7 \pm 0.2$ & & & $46 \pm 5$ \\
\hline $64.4 \pm 0.2$ & & & $91 \pm 10$ \\
\hline $64.7 \pm 0.2$ & & $43 \pm 4$ & \\
\hline $66.0 \pm 0.2$ & & & $49 \pm 5$ \\
\hline $66.5 \pm 0.4$ & & & $73 \pm 8$ \\
\hline $68.5 \pm 0.4$ & & & $51 \pm 6$ \\
\hline $70.5 \pm 0.4$ & & & $56 \pm 6$ \\
\hline $72.4 \pm 0.3$ & & & $53 \pm 6$ \\
\hline $74.5 \pm 0.3$ & & & $55 \pm 6$ \\
\hline $76.5 \pm 0.3$ & & & $45 \pm 5$ \\
\hline $78.5 \pm 0.3$ & & & $28 \pm 3$ \\
\hline $80.4 \pm 0.2$ & & & $41 \pm 5$ \\
\hline $82.3 \pm 0.2$ & & & $16 \pm 2$ \\
\hline $84.2 \pm 0.2$ & & & $22 \pm 2$ \\
\hline
\end{tabular}


Table 3. Measured cross sections for the formation of ${ }^{80 \mathrm{~m}} \mathrm{Br}$, utilising the ${ }^{80} \mathrm{Se}(p, n)^{80 \mathrm{~m}} \mathrm{Br}$ reaction.

\begin{tabular}{lc}
\hline $\begin{array}{l}\text { Proton energy } \\
(\mathrm{MeV})\end{array}$ & $\begin{array}{c}\text { Cross section } \\
(\mathrm{mb})\end{array}$ \\
\hline $7.4 \pm 0.4$ & $203 \pm 31$ \\
$8.7 \pm 0.4$ & $320 \pm 48$ \\
$10.1 \pm 0.4$ & $384 \pm 58$ \\
$11.3 \pm 0.3$ & $356 \pm 53$ \\
$11.7 \pm 0.3$ & $431 \pm 65$ \\
$13.1 \pm 0.3$ & $253 \pm 38$ \\
$13.3 \pm 0.3$ & $306 \pm 46$ \\
$14.4 \pm 0.3$ & $172 \pm 26$ \\
$15.2 \pm 0.3$ & $99 \pm 15$ \\
$15.7 \pm 0.3$ & $147 \pm 22$ \\
$16.8 \pm 0.3$ & $66 \pm 10$ \\
$18.5 \pm 0.3$ & $72 \pm 11$ \\
\hline
\end{tabular}

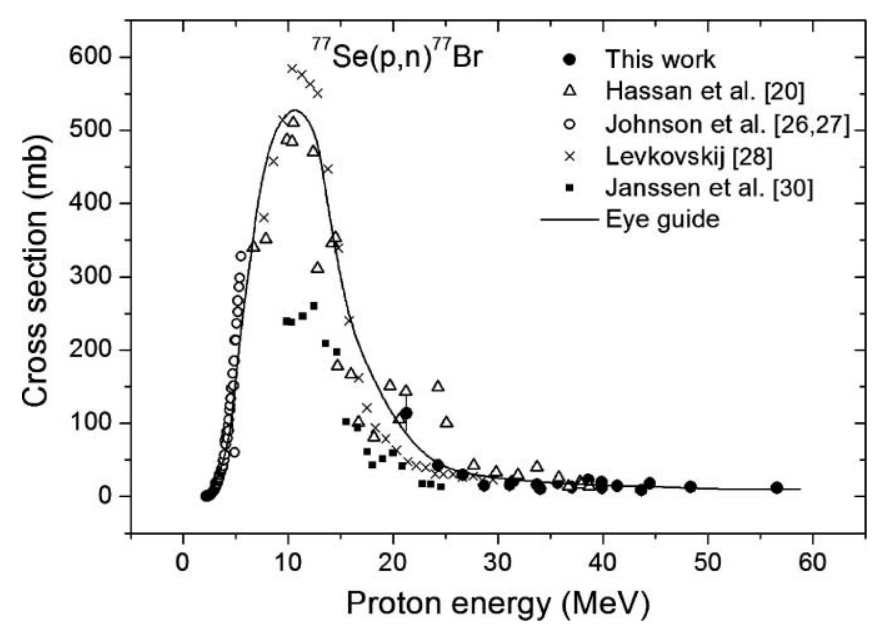

Fig. 1. Experimentally determined reaction cross sections for the formation of ${ }^{77} \mathrm{Br}$ using enriched ${ }^{77} \mathrm{Se}$ target material together with data from the literature. The data of Levkovskij [28] have been adjusted by $20 \%$ (see text).

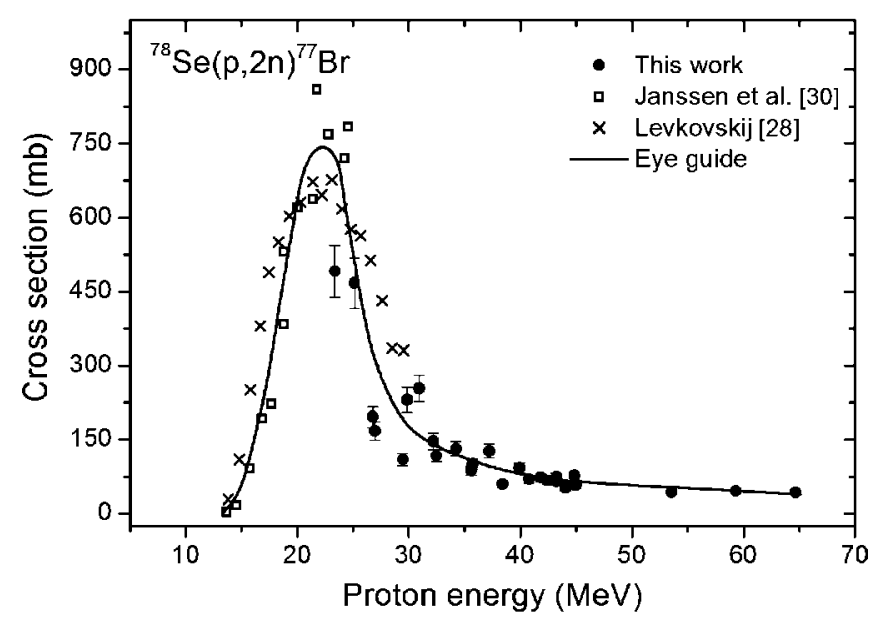

Fig. 2. Experimentally determined reaction cross sections for the formation of ${ }^{77} \mathrm{Br}$ using enriched ${ }^{78} \mathrm{Se}$ target material together with data from the literature. The data of Levkovskij [28] have been adjusted by $20 \%$ (see text).

data, in Figs. 1-4. The cross section data given in [25] are not included in Figs. 1-3, as those are based on the irradiation of natural target material and thus represent averaged

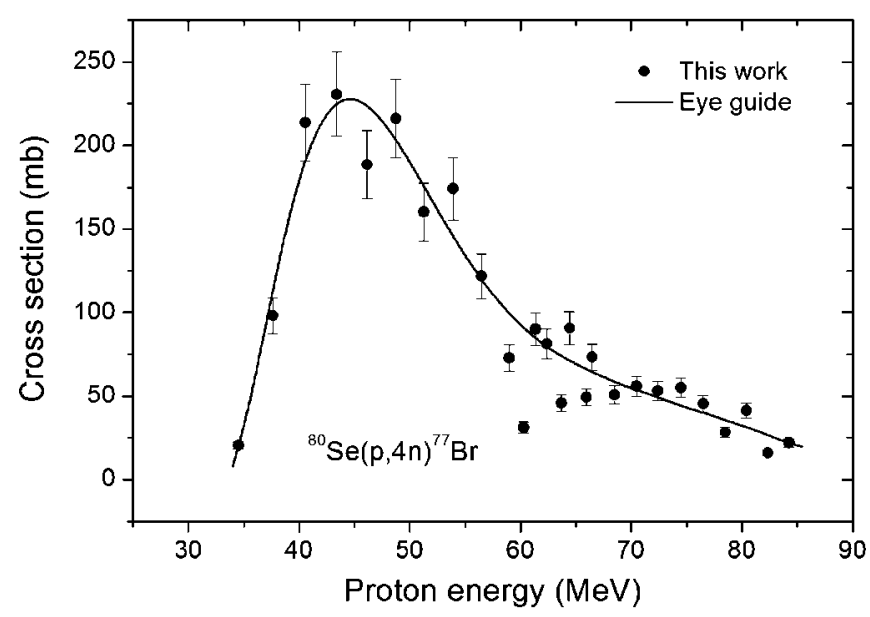

Fig. 3. Experimentally determined reaction cross sections for the formation of ${ }^{77} \mathrm{Br}$ using enriched ${ }^{80} \mathrm{Se}$ target material.

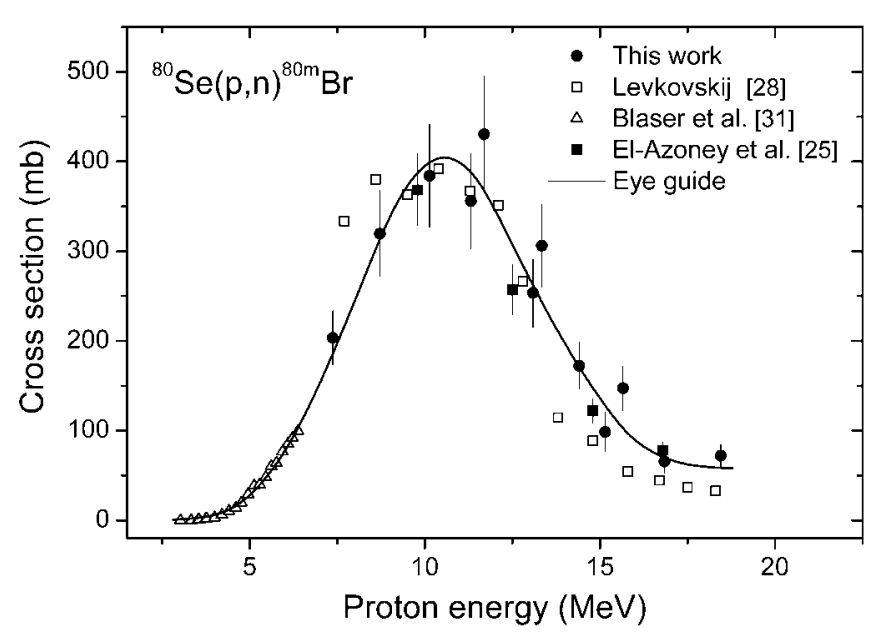

Fig. 4. Experimentally determined reaction cross sections for the formation of ${ }^{80 \mathrm{~m}} \mathrm{Br}$ using enriched ${ }^{80} \mathrm{Se}$ target material together with data from the literature. The data of Levkovskij [28] have been adjusted by $20 \%$ (see text).

results of competing reaction channels, which cannot easily be compared with the other data. In Fig. 4, however, the data are shown corrected for the isotope abundance of ${ }^{80} \mathrm{Se}$.

\subsection{1 ${ }^{77} \mathrm{Se}(p, n){ }^{77} \mathrm{Br}$ reaction}

The measured cross sections for the formation of ${ }^{77} \mathrm{Br}$ via the $(p, n)$ process using enriched ${ }^{77} \mathrm{Se}$ are depicted in Fig. 1 together with an eye-guided fit curve. This reaction has been investigated previously by different researchers. In the lowenergy range, Johnson et al. [26,27] reported data up to $5 \mathrm{MeV}$. In addition to the data published by Levkovskij [28], the excitation function was investigated by Hassan et al. [20] in the energy range between 5 and $40 \mathrm{MeV}$. The Levkovskij data were adjusted downwards by $20 \%$ according to the study of Takács et al. [29], who showed that those results were based on incorrect cross sections of the used Mo monitor foils. Nevertheless, there are some discrepancies concerning the maximum of the excitation function at about $11 \mathrm{MeV}$. The present measurements extend the data to about $57 \mathrm{MeV}$. It appears that our data suggest a broader shape of the excitation function than the results of Levkovskij and 
Janssen et al. [30]. The data by Hassan et al. [20] showed an increase in the cross section at energies between 20 and $25 \mathrm{MeV}$ due to an isotopic impurity of ${ }^{78} \mathrm{Se}(4.7 \%)$ in the sample. Combined with the older data of Johnson et al. [26, 27], in this work, a complete excitation function of the ${ }^{77} \mathrm{Se}(p, n)^{77} \mathrm{Br}$ reaction has been developed.

\subsection{2 $\left.{ }^{78} \mathrm{Se}(p, 2 n)\right)^{77} \mathrm{Br}$ reaction}

The newly measured cross section data on the ${ }^{78} \mathrm{Se}(p, 2 n)^{77} \mathrm{Br}$ reaction are shown in Fig. 2. For this reaction, two data sets existed in the literature $[28,30]$, covering the proton energy range from 14 up to 25 and $30 \mathrm{MeV}$, respectively. Our data provide the first experimental cross sections above $30 \mathrm{MeV}$. The rather slow decrease in cross section at higher proton energies implies that the $(p, 2 n)$ process on ${ }^{78} \mathrm{Se}$ may be useful for the production of ${ }^{77} \mathrm{Br}$. However, in this energy region production of the PET radionuclide ${ }^{76} \mathrm{Br}$ via the ${ }^{78} \mathrm{Se}(p, 3 n){ }^{76} \mathrm{Br}$ reaction would also occur, thereby reducing the radioisotopic purity of ${ }^{77} \mathrm{Br}(c f$. [5]). This aspect will be discussed in detail in Sect. 3.2.1.

\subsection{3 ${ }^{80} \mathrm{Se}(p, 4 n){ }^{77} \mathrm{Br}$ reaction}

Whereas the proton induced formation of ${ }^{77} \mathrm{Br}$ using natural selenium target material was studied earlier by Hassan et al. [20], Nozaki et al. [12] and El-Azony et al. [25], our work provides the first specific cross section measurements concerning the ${ }^{80} \mathrm{Se}(p, 4 n){ }^{77} \mathrm{Br}$ reaction channel. The data are shown in Fig. 3. In the energy region $59-66 \mathrm{MeV}$, our data show rather strong and unexpected scatter. In particular, some points appear to be too low compared with the other data. Due to that and with regard to the fact that the data shown are the results of repeated irradiation experiments, using the same set of samples, the most likely reason for the scatter is damage in one or two of the sediment samples. As mentioned in Sect. 2.1, those samples are rather fragile and some may have developed cracks or partial flattening during the preparation setup. Nevertheless, the remaining data points are sufficient to show the trend of the excitation function. A rather broad maximum can be observed at about $43 \mathrm{MeV}$, maintaining a significant magnitude up to $75 \mathrm{MeV}$ and beyond. Although the cross section values are significantly lower than those of the $(p, n)$ and $(p, 2 n)$ reactions, the width of the excitation function and the higher proton energy applied indicate that the $(p, 4 n)$ reaction may be useful for the production of ${ }^{77} \mathrm{Br}$. However, the possibility of co-producing isotopic impurities has to be analysed, which is discussed in detail below. There is, however, a clear disagreement between our data and the results given by El-Azony et al. Our measurements result in a cross section maximum at $40-45 \mathrm{MeV}$ of about $220 \mathrm{mb}$ using $99.90 \%$ enriched ${ }^{80} \mathrm{Se}$, whereas the maximum given by El-Azony et al. [25] obtained from irradiation of natural $\mathrm{Se}(49.6 \%$ ${ }^{80} \mathrm{Se}$ ) is about $270 \mathrm{mb}$ at the same proton energy. In comparison with the $(p, n)$ and $(p, 2 n)$ reaction cross section maxima, the data for this reaction given in this work appear to be more realistic, because they agree better with the proportional trend of the excitation functions of those reaction channels. However, additional work on the determination of the maximum cross section of the excitation function may be necessary.

\subsection{4 ${ }^{80} \mathrm{Se}(p, n)^{80 \mathrm{~m}} \mathrm{Br}$ reaction}

The cross section of the ${ }^{80} \mathrm{Se}(p, n)^{80 \mathrm{~m}} \mathrm{Br}$ reaction, systematically measured up to $18 \mathrm{MeV}$, is shown in Fig. 4 as a function of proton energy. In the low energy range some old cross section data on this nuclear process can be found $[28,31]$; the newest, however, are the data reported by Levkovskij in 1991, which are shown in Fig. 4 after downward adjustment as described in Sect. 3.1.1. In fact, no measurement detail has been given in that work, so that the authenticity of data cannot be ascertained. Our cross section values, nonetheless, agree rather well with Levkovskij's data: only a slight deviation at higher energies is observed. The data of El-Azoney et al. [25], which were obtained using natural target material, also agree with our new measurements if normalised to a theoretical $100 \%$ enrichment. A possible contribution resulting from the $(p, 3 n)$ reaction on ${ }^{82} \mathrm{Se}(9.4 \%)$ can be neglected within the investigated energy range. In the low energy range up to about $6.5 \mathrm{MeV}$ the data of Blaser et al. [31], obtained using a Geiger-counter, show a remarkably good agreement with our results. Our results on enriched ${ }^{80} \mathrm{Se}$, if normalised to ${ }^{\text {nat }} \mathrm{Se}$ as target, agree well with the recently published measurement of El-Azony et al. [25] on the ${ }^{\text {nat }} \mathrm{Se}(p, n)^{80 \mathrm{~m}} \mathrm{Br}$ reaction.

\subsection{Integral yield and radionuclidic purity}

Based on the new and better defined excitation functions presented in this work, the integral yields for the production of ${ }^{77} \mathrm{Br}$ and ${ }^{80 \mathrm{~m}} \mathrm{Br}$ using enriched Se targets were calculated. In Fig. 5, the calculated integral yields for the four nuclear reactions investigated in this work are shown as a function of projectile energy. For production purposes the proton induced reactions on Se are more effective than the reported alternative irradiations of $\mathrm{As}, \mathrm{Br}$ and $\mathrm{Kr}(c f .[9,11,15])$. For medical application, however, the radionuclidic purity of the product is also of crucial importance. In Table 4 the possible thick target yields are given for the production of ${ }^{80 \mathrm{~m}} \mathrm{Br},{ }^{77} \mathrm{Br}$ and the previously studied ${ }^{76} \mathrm{Br}$ together with potential radionuclidic impurities.

Although the production of ${ }^{80 \mathrm{~m}} \mathrm{Br}$ and ${ }^{77} \mathrm{Br}$ for medical application has been investigated earlier, the produc-

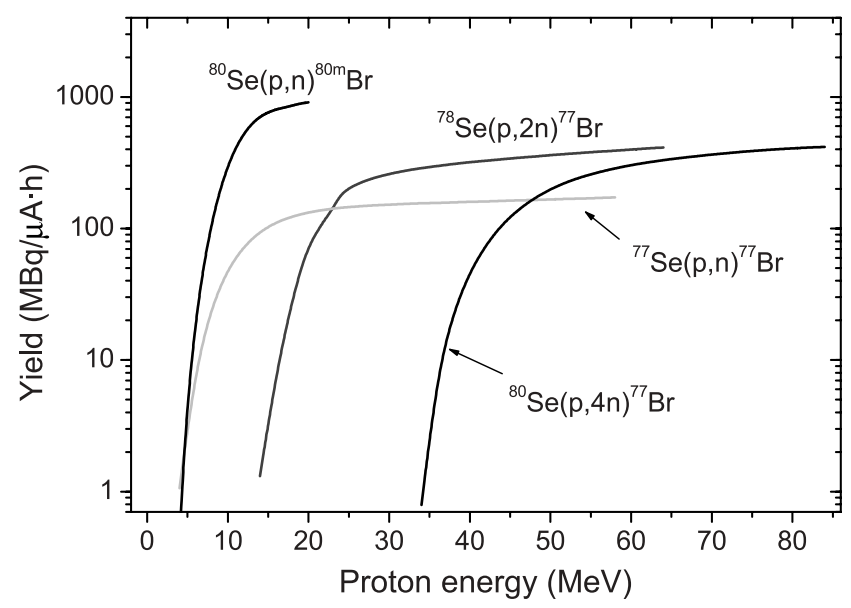

Fig. 5. Calculated integral yields of ${ }^{77} \mathrm{Br}$ and ${ }^{80 \mathrm{~m}} \mathrm{Br}$ based on the determined excitation functions (eye guide) of proton induced nuclear reactions presented in this work using enriched selenium target material. 
Table 4. Comparison of calculated production yields of ${ }^{76} \mathrm{Br},{ }^{77} \mathrm{Br}$ and ${ }^{80 \mathrm{~m}} \mathrm{Br}$ using different production energy ranges together with the corresponding radionuclidic impurities at the end of bombardment.

\begin{tabular}{lccc}
\hline & $\begin{array}{c}\text { Energy range } \\
(\mathrm{MeV})\end{array}$ & $\begin{array}{c}\text { Calc. yield } \\
\left(\mathrm{MBq} \mu \mathrm{A}^{-1} \mathrm{~h}^{-1}\right)\end{array}$ & Impurity \\
\hline${ }^{77} \mathrm{Se}(p, 2 n)^{76} \mathrm{Br}$ & $66 \rightarrow 14$ & 1320 & ${ }^{77} \mathrm{Br}(10 \%)$ \\
& $66 \rightarrow 22$ & 1033 & ${ }^{77} \mathrm{Br}(6 \%)$ \\
${ }^{78} \mathrm{Se}(p, 2 n){ }^{77} \mathrm{Br}$ & $26 \rightarrow 14$ & 219 & - \\
${ }^{80} \mathrm{Se}(p, 4 n){ }^{77} \mathrm{Br}$ & $86 \rightarrow 34$ & 422 & ${ }^{76} \mathrm{Br}(127 \%)$ \\
& $66 \rightarrow 34$ & 343 & ${ }^{76} \mathrm{Br}(91 \%)$ \\
${ }^{80} \mathrm{Se}(p, n){ }^{80 \mathrm{~m}} \mathrm{Br}$ & $50 \rightarrow 34$ & 199 & ${ }^{76} \mathrm{Br}(8 \%)$ \\
\hline
\end{tabular}

tion routes involving proton induced reactions on selenium did not receive much attention in the past. In 1979, Madhusudhan et al. [32] reported a thick target yield of about $66.5 \mathrm{MBq} \mu \mathrm{A}^{-1} \mathrm{~h}^{-1}$ for ${ }^{77} \mathrm{Br}$, using the ${ }^{78} \mathrm{Se}(p, 2 n)$ reaction. In 1982, Dimitriev et al. [33] reported thick target yields of about 46 and $51 \mathrm{MBq} \mu \mathrm{A}^{-1} \mathrm{~h}^{-1}$, respectively, for the production of ${ }^{77} \mathrm{Br}$ via proton and deuteron induced reactions on ${ }^{n a t} \mathrm{Se}$ in the energy range up to $22 \mathrm{MeV}$. A recent publication by El-Azony et al. [25] gives a calculated thick target yield of about $350 \mathrm{MBq} \mu \mathrm{A}^{-1} \mathrm{~h}^{-1}$ for ${ }^{77} \mathrm{Br}$ produced by proton induced reactions on natural $\mathrm{Se}$ at $60 \mathrm{MeV}$, which is in agreement with the data given by Nozaki et al. [12]. An extrapolation of our data to that target composition and energy range leads to about $300 \mathrm{MBq}$ of ${ }^{77} \mathrm{Br}$. For ${ }^{80 \mathrm{~m}} \mathrm{Br}$, El-Azony et al.

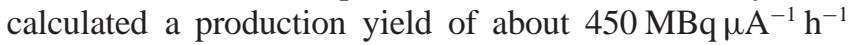
in the energy range of up to $15 \mathrm{MeV}$. By extrapolating the yield from ${ }^{\text {nat }} \mathrm{Se}$ to $100 \%{ }^{80} \mathrm{Se}$, this value agrees with the ${ }^{80} \mathrm{Se}(p, n){ }^{80 \mathrm{~m}} \mathrm{Br}$ reaction yield obtained in this work using enriched target material.

\subsubsection{Production of ${ }^{77} \mathrm{Br}$ with high radionuclidic purity}

Whereas all three investigated nuclear reactions allow the

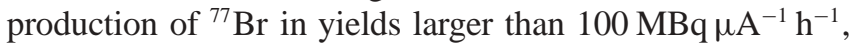
the $(p, 4 n)$ reaction on ${ }^{80} \mathrm{Se}$ causes an increased formation of radioactive co-products, especially ${ }^{76} \mathrm{Br}$ ( $c f$. Table 4$)$. The application of an incident proton energy of $50 \mathrm{MeV}$ for the irradiation of ${ }^{80} \mathrm{Se}$ leads to a reduction of ${ }^{76} \mathrm{Br}$ to about $8 \%$. The ${ }^{78} \mathrm{Se}(p, 2 n){ }^{77} \mathrm{Br}$ reaction, which shows the highest integral yield, appears to be the most promising nuclear process for the production of ${ }^{77} \mathrm{Br}$. In Fig. 6, the calculated integral yield of this reaction is shown together with the yield curves for the formation of ${ }^{75} \mathrm{Br}$ and ${ }^{76} \mathrm{Br}$, which was discussed in detail in the preceding paper [5]. The comparison indicates that the production of pure ${ }^{77} \mathrm{Br}$ using enriched ${ }^{78} \mathrm{Se}$ as target material is possible in the energy range $E_{\mathrm{p}}=26 \rightarrow 14 \mathrm{MeV}$,

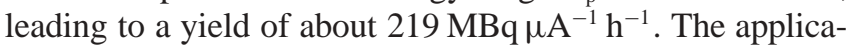
tion of higher incident proton energies will lead to higher yields up to $400 \mathrm{MBq}$. However, this would also increase the amount of ${ }^{76} \mathrm{Br}$ in the target, due to the initiation of the ${ }^{78} \mathrm{Se}(p, 3 n){ }^{76} \mathrm{Br}$ process.

\subsubsection{Production of ${ }^{80 \mathrm{~m}} \mathrm{Br}$ in high radionuclidic purity}

Concerning the production of ${ }^{80 \mathrm{~m}} \mathrm{Br}$, only the ${ }^{80} \mathrm{Se}(p, n)$ process was investigated, which proves to be highly effective for the production of this therapeutic radionuclide. The possible

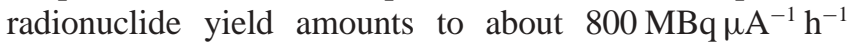

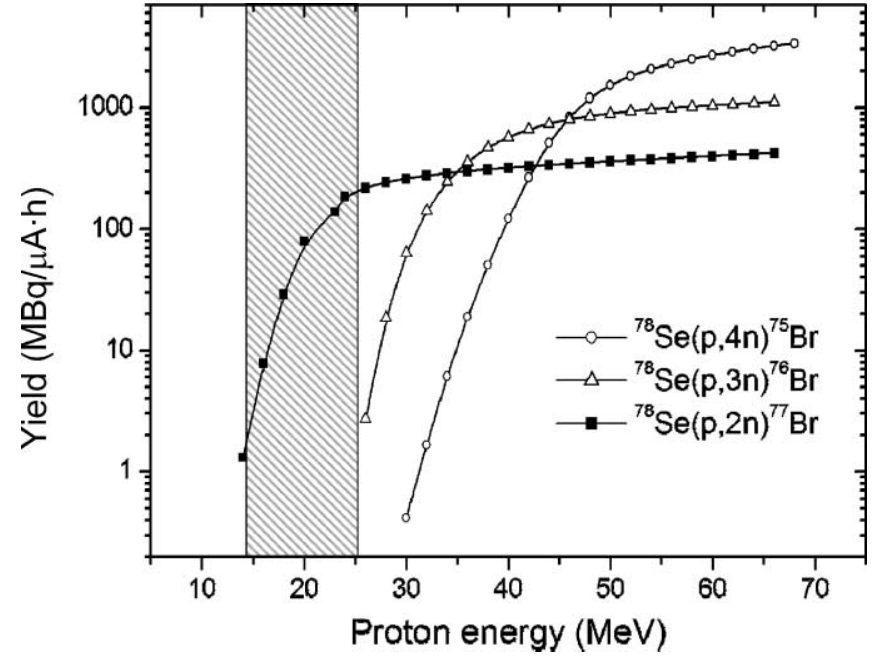

Fig. 6. Integral yield of ${ }^{77} \mathrm{Br}$ calculated from the fitted excitation function (eye guide) of the ${ }^{78} \mathrm{Se}(p, 2 n)^{77} \mathrm{Br}$ reaction in comparison with yield curves for the formation of ${ }^{75} \mathrm{Br}$ and ${ }^{76} \mathrm{Br}$. The shaded area gives the optimum energy range for the production of ${ }^{77} \mathrm{Br}$.

using an incident proton energy of $16 \mathrm{MeV}$. Furthermore, the measurements have shown that this nuclear reaction constitutes a very good application of small cyclotrons, which by now can be found in many medical facilities; thus allowing an efficient production of this promising radionuclide. If enriched ${ }^{80} \mathrm{Se}$ is used as target material, no relevant radioactive co-products are produced via this production route.

\section{Conclusion}

Nuclear reaction cross section data for the production of the medically interesting radionuclides ${ }^{77} \mathrm{Br}$ and ${ }^{80 \mathrm{~m}} \mathrm{Br}$ were experimentally determined, in the case of a few reactions for the first time. Based on the extended data, full excitation functions of the ${ }^{77} \mathrm{Se}(p, n){ }^{77} \mathrm{Br},{ }^{78} \mathrm{Se}(p, 2 n){ }^{77} \mathrm{Br}$, $\left.{ }^{80} \mathrm{Se}(p, 4 n)\right)^{77} \mathrm{Br}$ and ${ }^{80} \mathrm{Se}(p, n){ }^{80 \mathrm{~m}} \mathrm{Br}$ reactions could be developed. Possible radionuclide yields and associated isotopic impurities were calculated. With respect to the production of ${ }^{77} \mathrm{Br}$, the ${ }^{78} \mathrm{Se}(p, 2 n)$ reaction appears to be the most advantageous, although the choice of production energy range proved to be critical to obtain a high radionuclidic purity. The production of ${ }^{80 \mathrm{~m}} \mathrm{Br}$ via the ${ }^{80} \mathrm{Se}(p, n)$ process can be done with good efficiency and high purity at a small cyclotron. Regarding both the discussed bromine isotopes, the use of enriched target material is mandatory to achieve good yield and purity.

Acknowledgment. We thank the operators of the three cyclotrons for performing the irradiations. This work was done under a German Hungarian - South African cooperation and we thank all the involved authorities. The Hungarian authors thank the financial support from the Hungarian Research Foundation (K60223). This work was also supported in South Africa by NRF grant UID 62122. M. M. Shehata thanks the Egyptian government for a PhD scholarship tenable in Germany.

\section{References}

1. Qaim, S. M., Stöcklin, G.: Production of some medically important short-lived neutron deficient radioisotopes of halogens. Radiochim. Acta 34, 25-40 (1983). 
2. Coenen, H. H., Moerlein, S. M., Stöcklin, G.: No-carrier-added radiohalogenation methods with heavy halogens. Radiochim. Acta 34, 47-68 (1983).

3. Stöcklin, G.: Molecules labelled with positron emitting halogens. Nucl. Med. Biol. 13, 109-118 (1986).

4. Stöcklin, G., Paic, V. W. (Eds.): Radiopharmaceuticals for Positron Emission Tomography. Kluwer, Dordrecht (1993).

5. Spahn, I., Steyn, G. F., Vermeulen, C., Kovács, Z., Szelecsényi, F., Coenen, H. H., Qaim, S. M.: New cross section measurements for production of the positron emitters ${ }^{75} \mathrm{Br}$ and ${ }^{76} \mathrm{Br}$ via intermediate energy proton induced reactions. Radiochim. Acta 97, 535-541 (2009).

6. Maziere, B., Loc'h, C.: Radiopharmaceuticals labelled with bromine isotopes. Appl. Radiat. Isot. 37, 703-713 (1986).

7. Coenen, H. H.: New radiohalogenation methods: An overview. In: Progress in Radiopharmacology. (Cox, P. H., Mather, S. J., Sampson, C. B., Lazarus, C. R., eds.) Martinus Nijhoff Publishers, Dordrecht (1986), pp. 196-220.

8. Firestone, R. B.: Table of Isotopes. CD ROM edition, Version 1.0. Wiley Interscience, New York (1996).

9. Stöcklin, G.: Bromine-77 and iodine-123 radiopharmaceuticals. Int. J. Appl. Radiat. Isot. 28, 131-147 (1977).

10. Qaim, S. M., Blessing, G., Ollig, H.: Excitation functions of ${ }^{75} \mathrm{As}(\alpha, n){ }^{78} \mathrm{Br}$ and ${ }^{75} \mathrm{As}(\alpha, 2 n)^{77 \mathrm{~m}, \mathrm{~g}} \mathrm{Br}$ reactions from threshold to $28 \mathrm{MeV}$, Radiochim. Acta 39, 57-60 (1986).

11. Mease, R. C., DeJesus, O. T., Gatley, S. J., Harper, P. V., Desombre, E. R., Friedman, A. M.: Production of no carrier added ${ }^{80 \mathrm{~m}} \mathrm{Br}$ for investigation of Auger electron toxicity. Appl. Radiat. Isot. 42 57-61 (1990).

12. Nozaki, T., Iwamoto, M., Itoh, Y.: Production of ${ }^{77} \mathrm{Br}$ by various nuclear reactions. Int. J. Appl. Radiat. Isot. 30, 79-83 (1979).

13. Blessing, G., Weinreich, R., Qaim, S. M., Stöcklin, G.: Production of ${ }^{75} \mathrm{Br}$ and ${ }^{77} \mathrm{Br}$ via the ${ }^{75} \mathrm{As}\left({ }^{3} \mathrm{He}, 3 n\right){ }^{75} \mathrm{Br}$ and ${ }^{75} \mathrm{As}(\alpha, 2 \mathrm{n}){ }^{77} \mathrm{Br}$ reactions using $\mathrm{Cu}_{3}$ As-alloy as a high-current target material. Appl. Radiat. Isot. 33, 333-339 (1982).

14. Qaim, S. M.: Recent developments in the production of ${ }^{18} \mathrm{~F}$, ${ }^{75,76,77} \mathrm{Br}$ and ${ }^{123} \mathrm{I}$. Appl. Radiat. Isot. 37, 803-810 (1986).

15. Qaim, S. M., Stöcklin, G., Weinreich, R.: Excitation functions for the formation of neutron deficient isotopes of bromine and krypton via high-energy deuteron induced reactions on bromine: Production of ${ }^{77} \mathrm{Br},{ }^{76} \mathrm{Br}$ and ${ }^{79} \mathrm{Kr}$. Int. J. Appl. Radiat. Isot. 28, 947-953 (1977)

16. Dikšić, M., Galinier, J.-L., Marshall, H., Yaffe, L.: ${ }^{79} \mathrm{Br}$ and ${ }^{81} \mathrm{Br}(p, x n)$ and $(p, p x n)$ excitation functions in the energy range 10-85 MeV. Phys. Rev. C 19, 1753-1761 (1979).

17. De Jong, D., Kooiman, H., Veenboer, J. Th.: ${ }^{76} \mathrm{Br}$ and ${ }^{77} \mathrm{Br}$ from decay of cyclotron produced ${ }^{76} \mathrm{Kr}$ and ${ }^{77} \mathrm{Kr}$. Int. J. Appl. Radiat. Isot. 30, 786-788 (1979).

18. Weinreich, R., Knieper, J.: Production of ${ }^{77} \mathrm{Kr}$ and ${ }^{79} \mathrm{Kr}$ for medical applications via proton irradiation of bromine: excitation functions, yields and separation processes. Int. J. Appl. Radiat. Isot. 34, 1335-1338 (1983).

19. De Villiers, D., Nortier, M., Richter, W.: Experimental and theoretical excitation functions for ${ }^{\text {nat }} \operatorname{Br}(p, x)$ reactions. Appl. Radiat. Isot. 57, 907-913 (2002).

20. Hassan, H. E., Qaim, S. M., Shubin, Yu., N., Azzam, A., Morsy, M., Coenen, H. H.: Experimental studies and nuclear model calculations on proton-induced reactions on ${ }^{\text {nat }} \mathrm{Se},{ }^{76} \mathrm{Se}$ and ${ }^{77} \mathrm{Se}$ with particular reference to the production of the medically interesting radionuclides ${ }^{76} \mathrm{Br}$ and ${ }^{77} \mathrm{Br}$. Appl. Radiat. Isot. 60, 899-909 (2004).

21. Williamson, C. F., Boujot, J. P., Picard, J.: Tables of range and stopping power of chemical elements for charged particles of energies 0.5 to $500 \mathrm{MeV}$. Rapport CEA-R 3042, Saclay, France (1966).

22. Anderson, H. H., Ziegler, J. F.: Hydrogen stopping powers and ranges in all elements. In: The Stopping and Ranges of Ions in Matter. Pergamon, New York (1977), vol. 3, p. 1.

23. Szelecsényi, F., Steyn, G. F., Kovács, Z., Vermeulen, C., van der Meulen, N. P., Dolley, S. G., van der Walt, N. T., Suzuki, K., Mukai, K.: Investigation of the ${ }^{66} \mathrm{Zn}(p, 2 p n){ }^{64} \mathrm{Cu}$ and the ${ }^{68} \mathrm{Zn}(p, x){ }^{64} \mathrm{Cu}$ nuclear processes up to $100 \mathrm{MeV}$ : production of ${ }^{64} \mathrm{Cu}$. Nucl. Instrum. Methods Phys. Res. B 240, 625-637 (2005).

24. Tárkányi, F., Takács, S., Gul, K., Hermanne, A. Mustafa, M. G., Nortier, M., Obložinský, P., Qaim, S. M., Scholten, B., Shubin, Yu. N., Zhuang, Y.: Monitor reactions. In: Charged Particle Cross Section Database for Medical Radioisotope Production. IAEA-TECDOC-1211, International Atomic Energy Agency, Vienna (2001), pp. 49-152 (http://www-nds.iaea.org/medical/).

25. El-Azony, K. M., Suzuki, K., Fukumura, T., Szelecsényi, F., Kovács, Z.: Excitation functions of proton induced reactions on natural selenium up to $62 \mathrm{MeV}$. Radiochim. Acta 97, 71-77 (2009).

26. Johnson, C. H., Galonsky, A., Ulrich, J. P.: Proton strength functions from $(p, n)$ cross sections. Phys. Rev. 109, 1243-1254 (1958).

27. Johnson, C. H., Galonsky, A., Inskeep, C. N.: Cross sections for $(p, n)$ reactions in intermediate-weight nuclei. Progress Report, Oak Ridge National Lab. Reports, No. 2910 (1960), p. 25.

28. Levkovskij, V. N.: Activation Cross Sections for Nuclides of Average Masses $(A=40-100)$ by Protons and Alpha-Particles with Average Energies ( $E=10-50 \mathrm{MeV}$ ). Inter Vesi, Moscow (1991).

29. Takács, S., Tárkányi, F., Sonck, M., Hermanne, A.: Investigation of the nat $\operatorname{Mo}(p, x)^{96 \mathrm{mg}} \mathrm{Tc}$ nuclear reaction to monitor proton beams: new measurements and consequences on the earlier reported data. Nucl. Instrum. Methods Phys. Res. B 198, 183-196 (2002).

30. Janssen, A. G. M., van den Bosch, R. L.P, De Goej, J. J. M., Theelen, H. M. J.: The reactions ${ }^{77} \mathrm{Se}(p, n)$ and ${ }^{78} \mathrm{Se}(p, 2 n)$ for production routes for ${ }^{77} \mathrm{Br}$. Int. J. Appl. Radiat. Isot. 31, 405-409 (1980).

31. Blaser, J. P., Boehm, F., Marmier, P., Scherrer, P.: Anregungsfunktionen und Wirkungsquerschnitte der $(p, n)$-Reaktion (II). Helv. Phys. Acta 24, 441-464 (1951).

32. Madhusudhan, C. P., Treves, S., Wolf, A. P., Lambrecht, R. M.: Cyclotron isotopes and radiopharmaceuticals XXXI. Improvement in ${ }^{77} \mathrm{Br}$ production and radiochemical separation from enriched ${ }^{78}$ Se. J. Radioanal. Chem. 53, 299-305 (1979).

33. Dimitriev, P. P., Panarim, M. V., Dimitrieva, Z. P.: ${ }^{76} \mathrm{Br},{ }^{77} \mathrm{Br}$, and ${ }^{82} \mathrm{Br}$ yield in nuclear reactions with protons, deuterons, and alpha particles. Atom. Energ. 52, 72 (1982).

34. Experimental Nuclear Reaction Data (EXFOR), database version of 4 June (2008), NDS, IAEA (http://www-nds.iaea.org/exfor/ exfor00.htm). 